\title{
Effect of Standards of Selecting Jeans and Appearance Management Behavior on Leisure Lifestyle
}

\author{
Park Eunhee $\cdot$ Cho Hyunju* \\ Lecturer, Dept. of Home Economics, Kyungbook National University \\ Professor, Dept. of Home Economics, Kyungbook National University ${ }^{\star}$
}

\begin{abstract}
This study was to examine the effect of standards of selecting jeans and appearance management behavior on leisure lifestyle. Questionnaires were administered to 253 college students living in Deagu and Kyoungbuk. Data were analyzed by using frequency, factor analysis, regression analysis, t-test, and $\chi^{2}$-test. The findings are as follows. Factor structure of each concept appeared to be brand-valued, functionality valued and design-valued for standards of selecting jeans, diet management, exercise management, weight management and appearance satisfaction. Leisure lifestyle consisted of sports activity-type, sociality-type and self-management-type while value lifestyle consisted of active sociality-oriented, family-oriented and economic feasibility-oriented. There was a significant difference in brand-valued and design-valued of standards of selecting jeans and in frequency of wearing jeans male students showed higher than female students. The result of this study showed brand-valued, diet management, exercise management, weight management, and appearance satisfaction had significant effect on sports activity-type and design-valued and weight management had significant effect on sociality-type. Brand-valued affected self-management-type significantly and brand-valued, design-valued, diet management and appearance satisfaction had a significant effect on active sociality-oriented and brand-valued and diet management affected family-oriented.
\end{abstract}

Key Words : Standards of Selection Jean, Appearance Management Behavior, Leisure Lifestyle

\section{Introduction}

With the development of information and technology, modern society has brought average life extension, paid vacations, and improvement of national living standard, and people have more leisure time from five-day workweek and saturday-off, which makes people think their leisure time to be more important in their life. Leisure becomes more important for people in

Corresponding author; Cho, Hyunju, Tel. +82-53-950-5927, Fax.+82-53-950-5924

E-mail:pgjo@wmail.knu.ac.kr 
Park Eunhee - Cho Hyunju / Effect of Standards of Selecting Jeans and Appearance Management Behavior on

contemporary world to increase the quality of life by their favorite activities off from works and by various leisure activities such as trips, leisure sports, self-improvement, and entertainments according to their taste. Furthermore, leisure activities are the very core factor of life as people's passive perception on them has become more active one to pursue the improvement of life quality and selfdevelopment. ${ }^{1)}$

According to actual state examination on adolescents, watching TV appeared to be top for spending leisure time followed by using computers, meeting friends, video programs, and leisure activities, and the way and the place they spend their time differed as various taste of them. Products they consume also varied by their personal characteristics. These adolescents have way of thinking and way of behavior under a network environment, which would show difference from those in other ages. Accordingly this new generation would soon become economically independent to consume selfsupportingly, which requires marketing practitioners to understand tendency of these new generation customers, to evaluate and analyze the characteristics of them earlier than competitors. Consumers usually make purchase decisions according to the evaluation on products in their purchas decision making process. In this way, the evaluation standards for product consumers use include both objective characteristics of products and subjective characteristics of consumers' perception on which interrelationship lies. ${ }^{2)}$ That is, consumers apply objective standards such as the fit, fabric, ruggedness, practicality, ease of management of clothes as well as subjective standards such as fashionableness, swellishness, dignity, intrinsic symbolic social position, sexual image or esthetic image to buying apparel products. $^{3)}$ Especially jeans have been recognized as practical apparel products which everybody can wear regardless of gender or season. Recently jeans with the design that emphasize the body line as emotional fashion products have been preferred. Furthermore consumers can have more chances in jean-selection as various products with aesthetic and functionality such as denim with spandex, pattern-design, and already-washed have been offered. World-wide tendency toward casual clothes and changes in lifestyle due to five-day workweek were connected to the interest in jeans. Jeans are emerging as an item which can be more expressed in various design and colors by the structure or methods of washing or producing than other materials. ${ }^{4)}$ On the other hand, there have been studies related to actual states of wearing jeans, jean-wearing attitude of female university students with design of jeans by residence areas, difference in standards of evaluating jeans by gender of university students and etc. ${ }^{5(6) 788)}$, which calls for the necessity of studies related to standards of jean-selection and market segmentation variables.

Accordingly university students are trying to change themselves through appearance management fitting personal tastes and body conditions rather than others' opinion as they put values on their appearance by their preference and they are free and open. ${ }^{9)}$ Therefore this study is to understand the leisure lifestyle and values by grasping the standards of selection when buying jeans and appearance management behavior subjected to university students who are main consumer class of jeans. This study can be a necessary index for differentiated market segmentation by examining the relationship of standards of jean-selection 
related to clothing behaviors in specific situations as leisure activities of university students considering the trend that the lifestyle of modern people is to pursue the quality of life.

\section{Background}

\section{Standards of selecting jeans and actual state of wearing jeans}

Standards of selecting products are the attributes of the products consumers use to compare and evaluate various substitutes in selecting products. The attributes considered when buying apparel products vary from main purpose of product buying or the benefits and situation.

Rhee Eunyoung grouped standards of selecting clothes into intrinsic characteristics which include style, color, design and fabric structure of clothes and extrinsic characteristics such as price or brand name and etc. ${ }^{10)}$

Park Wonsun and Lee Sunjae found the standards in buying jeans were fitting body shape, design, colors and etc. This result showed more importance in fashion than in practicality, which requires skilled design works and pattern works in manufacturing jeans considering body shapes. ${ }^{11)}$ Lee Joungsuk and Sung Sukwang compared the number of jeans they have, image of jeans and etc. of those in 18s-23s wearing jeans by gender. The result showed male students chose jeans first by their own style, not considering designs, and by fashion in an order while female students chose jeans first by their own style, by fashion and not considering designs in an order. Female students have higher tendency of fashion pursuit than male students, which resulted in the difference of jeans style of their preference. ${ }^{12)}$ Lim Jiyoung found important considerations in buying jeans as price came first followed by design and fashion in 10s-30s and those in their 40s and 50s put more importance on fit than in fashion and design. lower aged people put more importance on fashion and higher aged people put more importance on fit. ${ }^{13)}$ Chun Jonhsuk and Suh Minjung found $45.5 \%$ of women and $25.9 \%$ of men wore jeans more than 3 days a week and women in their 20s were $54.6 \%$. They found both men and women in 20s wore more frequently than $30 \mathrm{~s} .{ }^{14)} \mathrm{Kim}$ Sonhee, Kim Hyesoo and Jeon Misun examined wearing attitude of female university students by residing areas with jeans of different rise-length and found a significant difference in the importance level of their evaluation standards such as silhouette, wear, design different from where they live. In other words, items such as use, color, price, size, and for coordination with tops were shown important as evaluation standards in an order of Seoul, Kyounggido, other local areas and items of material and durability were Seoul, other local areas, Kyounggido and items of wear, brand, silhouette, advice of others were Seoul, local areas, and Kyounggido. ${ }^{15)}$ Park Nari and Park Jaeok found women consumers considered quality standards such as durability and elasticity and aesthetic standards such as color, design and washing process state more important than men consumers as product characteristics considered when buying jeans. And university students wore jeans almost everyday or more than 3-4 times a week, generally had more than 3 jeans, and they purchased at least $1-2$ jeans in past year. ${ }^{16)}$ Accordingly, this study tries to figure out the actual state of wearing jeans by understanding the standards of selecting jeans among 
Park Eunhee - Cho Hyunju / Effect of Standards of Selecting Jeans and Appearance Management Behavior on

university students who are main consumer class of jeans.

In this way, previous studies were related to the selection standards according to the demographic characteristics of those wearing jeans by age. This study tried to examine the selection standards related to leisure lifestyle which is one of personal characteristics.

\section{Leisure lifestyle and appearance management behavior}

Lifestyle is a unique mode of people's living in a society and this is an element differentiates one from another. It's also a differentiated way of a person's or a group's life actualized by activity areas, interested fields, attitude and values, which is mainly used to view overall differences in living among different groups or classes. ${ }^{17)}$ Rhee Eunyoung suggested individual life space is formed according to values and expectations of culture, society and groups and this individual life space can be divided into consciousness space and activity spaces, which affect forming of lifestyle. ${ }^{18)}$

Lifestyle can be classified largely into macroscopic analysis and microscopic analysis. Macroscopic analysis focuses on figuring out overall lifestyle trend of all or several parts of a society while microscopic analysis refers to individual lifestyle according to specific daily role and activities. Especially microscopic analysis is needed to illuminate the individual gap such as what kind of people would be well expressing new trend. ${ }^{19)}$ As microscopic analysis is a method to figure out or predict social trends by analyzing the pattern of consumers' values and living habits, it is used in marketing or consumer behavior analysis, and $\mathrm{AlO}$ (Activity, Interest, Opinion) analysis and value analysis are its representative methods. ${ }^{20)} \mathrm{AlO}$ analysis measures
3 dimensions such as interest in daily activities, things around and opinion on social problems to classify the types for utilization. Psychographics analysis which more extensive than $\mathrm{AlO}$ analysis uses personal characteristic variables such as personality, value, and belief to figure out the inner backgrounds of outer behavior for classification and utilization of lifestyle types.

On the other hand, there's another opinion that it is proper to classify the types as clothing habits, dietary life, and housing rather than considering overall life of consumers as one. With respect to this opinion, Chai Seoil divided lifestyle into 8 types such as clothingdiet-housing, cultural life, using media, shopping manner, personality types, social values, which were grouped into traditional savingness type, rational life-satisfaction type, progressive fashion -pursuing type, conservative life-indifference type. $^{21)}$

From the result of these studies, leisure lifestyle was used for this study.

Leisure refers to an active process of getting satisfactions through voluntary participation to realize desires of each person and to improve the quality of life under the conditions fulfilled with time, economic and psychological situations available for a person. ${ }^{22)}$ Leisure activities can be classified by motives and expression styles into physical activities, sociable activities, cultural activities, natural activities, mental activities. ${ }^{23)}$ Leisure activities of university students are sociable activities which refer to the activities in usual daily life, activities for self-management, and the activities of participating in sports directly or indirectly. Like this, leisure life can be defined as usual daily physical, mental, cultural and sociable activities including personal preference, taste and values. And this leisure life is based on psychological variables such as attitude and values under the behavior, so it is 
possible to include value lifestyle in leisure lifestyle. This lifestyle is frequently used for building marketing strategies as it can be utilized as a useful standard to explain the characteristics of markets which can not be explained by demographic variables.

Hong Sungtai and Park Euna extracted factors of clothing-food-housing life, leisure life, social/ environmental view, home life, health management, beauty management, overal buying behavior from women's lifestyle. Based on these factors they classified 6 groups(decreased will type, self-centered type, frugal faithful type, active lively type, conservative stability type) and these types were used as an index for segmented markets. ${ }^{24)}$ Ahn Jooah and Shin Myounghee integrated measures overlapped with VALS and LOV based on AIO with the purpose of segmenting university students, and removed the measures which do not match Korean social system and values and again modified for the level of university students. These variables were materialized into passive realistic type, progressive fashion-pursuing type, conservative optimistic type. ${ }^{25)}$ Cho Sunmyoung and Koh Aeran extracted clothing life are, food life area, housing life area, leisure life area, consumption life area, values area from lifestyle subjected to consumers of male and female sports apparel products. ${ }^{26)}$ Je Eunsuk suggested differentiated and segmented data in leisure fashion markets by studying standards of selecting clothes in specific situation as leisure activities of consumers in 20s and 30s. The leisure activities consisted of factors as sociality activity, sports activity, hobby-culture activity, resting activity and trip activity and the result of cluster analysis for these factors showed 4 groups such as leisure indifference group, trip activity group, hobby-sports activity group and sociality activity group. In difference of standards in selecting clothes by leisure activity consumer group, intrinsic standards and extrinsic standards scored high while in trip activity group and sociality acivity group, intrinsic standards scored high. In standards of selecting clothes by age and gender of leisure activity group, women group showed higher scores than men group. ${ }^{27)}$

Unlike common idea in the past that appearance is given from the birth, modern sociocultural idea that appearance should be made and managed increases the needs of people for appearance management. ${ }^{28)}$ Female students who had more interest in appearance showed more experiences of various appearance management behaviors to maintain ideal ones. ${ }^{29)}$ This kind of idea has increased awareness of male students to get more interested in appearance enough to take some skin care services. ${ }^{30)}$ This kind of appearance management services and products are reached through mass media leading them to have needed leisure activities.

We can figure out consuming life by studying where, how and with whom consumers spend time of a day and we can understand leisure life related to those information. Based on this fact, understanding life style must be necessary to analyze consuming culture of university students and to build some marketing strategies. As psychological variables which are invisible such as values, attitude and personal characteristics are the base variable to decide the direction of behavior, it is required to study the difference among these base variables to predict consumer behavior. ${ }^{31)}$ Accordingly this study tried to understand the leisure life, values and appearance management behavior which are part of lifestyle. 
Park Eunhee - Cho Hyunju / Effect of Standards of Selecting Jeans and Appearance Management Behavior on

\section{Methods}

\section{Research problems}

1. to understand the factor structure of standards of selecting jeans, appearance management behavior and leisure lifestyle.

2. to find out the standards of selecting jeans and actual state of wearing jeans by gender.

3. to examine the effect of standards of selecting jeans and appearance management behavior on leisure lifestyle.

\section{Data collection and analysis}

A pilot test was done before main examination subject to university students in Daegu and Kyoungbuk area through Feb. 2012, and from the result of the pilot test main survey questions are built. 270 survey questionnaires for main study were distributed to university students in Daegu and Kyoungbuk area through Mar. 10 Mar. 20, 2012 and except for unsincere replies total 253 were used for data analysis. Data showed the sex rate as 138 male students(54.5\%) and 115 female students(45.5\%) and age groups as 145(57.3\%) for 18-20, $71(28.1 \%)$ for $21-23$ and $37(14.6 \%)$ for $24-27$.

SPSS PC+ 18.0 was used for data analysis with frequency analysis, factor analysis, regression analysis, t-test and $\chi^{2}$-test.

\section{Measures and process}

Survey method was used to collect data for this study and the measures such as standards of selecting jeans, appearance management behavior and leisure lifestyle consisted of 5-point Likerties scale(1: strongly agree, 5: strongly disagree)

Standards of selecting jeans refers to attributes of jeans considered when buying and it's the benefit which consumers want to get from jeans. This study used 11 question items modified and supplemented by the authors on the basis of previous studies ${ }^{32) 33)}$ to examine standards of selecting jeans. Appearance management behavior refers to the behavior of an individual' managing the appearance with the recognition of the importance which the appearance has in personal relations, which used 12 items modified and supplemented by the authors on the basis of previous studies. ${ }^{34)}$ Leisure lifestyle refers to activities for relaxation, refreshment, selfimprovement, and social participation in free states from social duties which used 20 items modified and supplemented by the authors on the basis of previous studies. ${ }^{35)}$ To examine actual state of wearing jeans, frequency of wearing jeans, rise length and the number of jeans purchased were used with demographic variables as gender and age.

\section{Results and discussion}

\section{Factor structure of standards of jean- selection, appearance management behavior and leisure lifestyle.}

As a result of factor analysis with principal component analysis and Varimax rotation to understand the standards of jeans-selection, 3 factors were extracted as <Table 1> below. Factor 1 refers to the behavior of selecting brands that can match people around and preferring jeans with brand logo appeared on, which was named 'brand-valued'. Factor 2 was named as 'functionality-valued' as they prefer jeans which are strong and practical and are wearable. Factor 3 consisted of items about the behavior of selecting the design that goes with 
other clothes, that makes body look better and that fits their own images, which was named as 'design-valued'. The factors' credibility test showed .80 for factor 1, .74 for factor 2, and .67 for factor 3 in Cronbach' $\alpha$ with total explanation of $56.84 \%$.

The result of average analysis with 5-point scale of standards of selecting jeans(1: strongly agree, 5: strongly disagree) showed that university students put importance on design that make body shapes look better and on balance with other clothes they have. This shows the way university students select jeans for comfortable life on campus and for better looking of their bodies.

As a result of factor analysis with principal component analysis and Varimax rotation to understand appearance management of university students, 4 factors were extracted as $<$ Table 2> below. Factor 1 is named as 'diet management' as it includes items of trying to improve diet habits for health and controlling the amount of foods. Factor 2 refers to the behavior of keeping exercising regularly and risking the expense for things needed to exercise, which is named 'exercise management'. Factor 3 refers to 'weight management' with facts that they need to lose weights and they want to weigh less than now. In factor 4, students felt self-confidence in their appearance and they felt they're nice-looking, which was named as 'appearance satisfaction'. The factors' credibility test showed .85 for factor $1, .73$ for factor 2 , . 87 for factor 3 and .87 for factor 4 in Cronbach' $\alpha$ with total explanation of $73.42 \%$.

The result of average analysis with 5-point scale of standards of selecting jeans(1: strongly agree, 5: strongly disagree) showed weight manamgement was highest followed by diet management, exercise management and appearance satisfaction and university students are highly interested in their weights thinking it's

$<$ Table 1> Factor analysis for standards of selecting jeans

\begin{tabular}{|c|c|c|c|c|c|}
\hline Factors & Variables & Loading & $\begin{array}{l}\text { Eigen } \\
\text { value }\end{array}$ & \begin{tabular}{|c|} 
Accumulation \\
variance(\%)
\end{tabular} & $\begin{array}{c}\text { Cronbach's } \alpha \\
\text { (Mean) }\end{array}$ \\
\hline $\begin{array}{l}\text { Brand- } \\
\text { valued }\end{array}$ & $\begin{array}{l}\text { I select brands that go with people around } \\
\text { me. } \\
\text { I select brands that have brand logos on } \\
\text { jeans. } \\
\text { I tend to select products of famous brands. } \\
\text { It's important to wear clothes in fashion. } \\
\text { I select jeans by the fabric(quality, thickness, } \\
\text { elasticity) in fashion rather than design. }\end{array}$ & $\begin{array}{l}.83 \\
.77 \\
.72 \\
.52 \\
.51\end{array}$ & 2.40 & 21.79 & $\begin{array}{c}.80 \\
(2.79)\end{array}$ \\
\hline $\begin{array}{l}\text { Functio } \\
\text { nality- } \\
\text { valued }\end{array}$ & $\begin{array}{l}\text { Jeans are stronger and more practical than } \\
\text { other clothes. } \\
\text { Jeans are wearable. } \\
\text { Jeans are easy to be washed and managed. }\end{array}$ & $\begin{array}{l}.82 \\
.81 \\
.78\end{array}$ & 2.01 & 40.06 & $\begin{array}{c}.74 \\
(2.33)\end{array}$ \\
\hline $\begin{array}{l}\text { Design- } \\
\text { valued }\end{array}$ & $\begin{array}{l}\text { I select jeans considering the balance with } \\
\text { other clothes I have. } \\
\text { I select jeans of the design that makes my } \\
\text { body look better. } \\
\text { I select jeans that go with my image. }\end{array}$ & $\begin{array}{l}.82 \\
.77 \\
.71\end{array}$ & 1.85 & 56.84 & $\begin{array}{c}.67 \\
(2.19)\end{array}$ \\
\hline
\end{tabular}


Park Eunhee - Cho Hyunju / Effect of Standards of Selecting Jeans and Appearance Management Behavior on

needed to lose weight, while their selfconfidence in appearance was below average.

A principal component analysis and a factor analysis using Varimax rotation were used to examine the leisure lifestyle of university students. As a result, 3 factors were extracted for leisure lifestyle as in $\langle$ Table 3$\rangle$. Factor 1 referred to behavior that directly plays sports rather than watches them and that regularly exercise, which was named as 'sports-activity type'. Factor 2 was named as 'sociality type' for the behavior of participating often in meeting

$\langle$ Table 2> Factor analysis for appearance management behavior

\begin{tabular}{|c|c|c|c|c|c|}
\hline Factors & Variables & Loading & $\begin{array}{l}\text { Eigen } \\
\text { value }\end{array}$ & $\begin{array}{c}\text { Accumulation } \\
\text { variance(\%) }\end{array}$ & $\begin{array}{c}\text { Cronbach's } \alpha \\
\text { (Mean) }\end{array}$ \\
\hline $\begin{array}{c}\text { Diet } \\
\text { management }\end{array}$ & $\begin{array}{l}\text { I'm going to improve my diet for health. } \\
\text { I'm trying to have a good diet habit. } \\
\text { I'm controlling food amount considering my } \\
\text { health. } \\
\text { At least I'm having foods thinking of good } \\
\text { foods for my body. } \\
\text { I'm considering calories when eating foods. }\end{array}$ & $\begin{array}{l}.89 \\
.87 \\
.75 \\
.66 \\
.65\end{array}$ & 3.12 & 26.02 & $\begin{array}{c}.85 \\
(2.95)\end{array}$ \\
\hline $\begin{array}{c}\text { Exercise } \\
\text { management }\end{array}$ & $\begin{array}{l}\text { I exercise for } 30 \text { minutes more than } 2 \\
\text { times a week. } \\
\text { I exercise at least for } 10 \text { minutes a day for } \\
\text { my health. } \\
\text { I risk cost for products needed for } \\
\text { exercising. }\end{array}$ & $\begin{array}{l}.86 \\
.83 \\
.68\end{array}$ & 2.00 & 42.65 & $\begin{array}{c}.73 \\
(2.96)\end{array}$ \\
\hline $\begin{array}{c}\text { Weight } \\
\text { management }\end{array}$ & $\begin{array}{l}\text { I think I need to lose my weight. } \\
\text { I want to weigh less than now. }\end{array}$ & $\begin{array}{l}.91 \\
.90\end{array}$ & 1.92 & 58.62 & $\begin{array}{c}.87 \\
(2.45) \\
\end{array}$ \\
\hline $\begin{array}{l}\text { Appearance } \\
\text { satisfaction } \\
\end{array}$ & $\begin{array}{l}\text { I have self-confidence in my appearance. } \\
\text { I think I'm nice-looking. }\end{array}$ & $\begin{array}{l}.93 \\
.93 \\
\end{array}$ & 1.78 & 73.42 & $\begin{array}{c}.87 \\
(3.23) \\
\end{array}$ \\
\hline
\end{tabular}

$<$ Table 3> Factor analysis for leisure lifestyle

\begin{tabular}{|c|c|c|c|c|c|}
\hline Factors & Variables & Loading & $\begin{array}{l}\text { Eigen } \\
\text { value }\end{array}$ & $\begin{array}{c}\text { Accumulation } \\
\text { variance(\%) }\end{array}$ & $\begin{array}{c}\text { Cronbach's } \alpha \\
\text { (Mean) }\end{array}$ \\
\hline $\begin{array}{l}\text { Sports- } \\
\text { activity } \\
\text { type }\end{array}$ & $\begin{array}{l}\text { I play sports rather than watch them. } \\
\text { I usually exercise often. } \\
\text { I regularly play my favorite sports. } \\
\text { I spend my leisure time exercising. } \\
\text { I enjoy adventurous sports. }\end{array}$ & $\begin{array}{l}.82 \\
.80 \\
.78 \\
.74 \\
.72\end{array}$ & 3.57 & 35.71 & $\begin{array}{c}.90 \\
(3.35)\end{array}$ \\
\hline $\begin{array}{l}\text { Sociality } \\
\text { type }\end{array}$ & $\begin{array}{l}\text { I often participate in meetings with friends or } \\
\text { in alumni meetings. } \\
\text { I enjoy meeting people in dinner time. }\end{array}$ & .87 & 1.60 & 51.68 & $\begin{array}{c}.69 \\
(2.44)\end{array}$ \\
\hline $\begin{array}{l}\text { Self- } \\
\text { manage } \\
\text { ment } \\
\text { type }\end{array}$ & $\begin{array}{l}\text { I have been to language studies or I'm going } \\
\text { to go abroad for language studies. } \\
\text { I want to trip overseas in vacations. } \\
\text { I have had time feeling alone or blue in spare } \\
\text { time in weekdays or weekend. }\end{array}$ & $\begin{array}{l}.67 \\
.65\end{array}$ & 1.46 & 66.29 & $\begin{array}{c}.50 \\
(2.49)\end{array}$ \\
\hline
\end{tabular}


friends or alumni meetings and enjoying meeting friends in dinner time. Factor 3 was 'selfmanagement type' that consists of behaviors that plan to go abroad for language studies and want to have overseas trips. The result of credibility test for 3 factors showed Cronbach' $\alpha$ for factor 1 was .90, factor 2, .69 and factor 3, .50 with the explanation of $66.29 \%$.

The explanation was high in 'sports-activity type' and the result of average analysis from 5-point scale(1: strongly agree, 5: strongly disagree) showed explanation sociality type, self-management type, and sports-activity type in an order, which means university students enjoy having some meetings with friends and they seemed to have high intention to manage themselves through some experiences of training in public or in private.

As a result of factor analysis with principal component analysis and Varimax rotation to understand the value lifestyle of university students, 3 factors were extracted as <Table $4>$ below. Factor 1 was named as 'active socialityoriented' as they love to get along with others and want to be a leader among the group they belong to. Factor 2 consists of items that tell us people of this type spend much time talking with family members and they take trips by family, which was named 'family-oriented'. Factor 3 was named as 'material-oriented' with items that showed behaviors of thinking of economic feasibility to be important in living and of material affluence to be a core factor for a happy life. The factors' credibility test showed .68 for factor $1, .74$ for factor 2 , and .73 for factor 3 in Cronbach' $\alpha$ with total explanation of $60.40 \%$.

The result of average analysis with 5-point scale of value lifestyle(1: strongly agree, 5: strongly disagree) showed that present university

$<$ Table 4> Factor analysis for value lifestyle

\begin{tabular}{|c|c|c|c|c|c|}
\hline Factors & Variables & Loading & $\begin{array}{l}\text { Eigen } \\
\text { value }\end{array}$ & $\begin{array}{l}\text { Accumulation } \\
\text { variance(\%) }\end{array}$ & $\begin{array}{c}\text { Cronbach's } \alpha \\
\text { (Mean) }\end{array}$ \\
\hline $\begin{array}{l}\text { Active } \\
\text { sociality- } \\
\text { oriented }\end{array}$ & $\begin{array}{l}\text { I like getting along with others } \\
\text { I want to lead a group which I belong to. } \\
\text { I tell my feelings or thoughts openly to others. } \\
\text { I try to give variety to my daily life. }\end{array}$ & $\begin{array}{l}.74 \\
.73 \\
.71 \\
.68\end{array}$ & 2.07 & 20.66 & $\begin{array}{c}.68 \\
(2.80)\end{array}$ \\
\hline $\begin{array}{l}\text { Family- } \\
\text { oriented }\end{array}$ & $\begin{array}{l}\text { I often take trips with family members } \\
\text { altogether. } \\
\text { I spend my vacation mostly with my family } \\
\text { members. } \\
\text { I have much time talking with my family } \\
\text { members. }\end{array}$ & $\begin{array}{l}.89 \\
.82 \\
.71\end{array}$ & 2.00 & 40.63 & $\begin{array}{c}.74 \\
(3.14)\end{array}$ \\
\hline $\begin{array}{l}\text { Material- } \\
\text { oriented }\end{array}$ & $\begin{array}{l}\text { Economic feasibility is more important than } \\
\text { other things in living a life. } \\
\text { Material affluence is needed for a happy life. } \\
\text { A fruitful job should be premised with high } \\
\text { salary. }\end{array}$ & $\begin{array}{l}.85 \\
.82 \\
.74\end{array}$ & 1.98 & 60.40 & $\begin{array}{c}.73 \\
(2.45)\end{array}$ \\
\hline
\end{tabular}


Park Eunhee - Cho Hyunju / Effect of Standards of Selecting Jeans and Appearance Management Behavior on Leisure Lifestyle

students think economic feasibility to be important in their values.

\section{Difference in standards of selecting jeans and actual state of wearing jeans by gender}

$<$ Table 5> shows the result of t-test to understand the difference in standards of jeans-selection by gender and a significant difference was found in brand-valued and design-valued. Male students showed higher score in brand-valued while female students showed higher in design-valued. This is similar to that of Park Nari and Park Jaeok's study ${ }^{36)}$ which found that aesthetic standards were more important in product characteristics considered when buying jeans.

$<$ Table 6> shows the result of $\chi^{2}$-test to understand the difference in frequency of the actual states of wearing jeans by gender of university students. The actual states of wearing jeans are about the frequency of wearing jeans in a week, a rise length, the number of jeans purchased in a year, which showed a difference by gender. Male students wore jeans more than

$<$ Table 5> Difference in standards of selecting jeans by gender

\begin{tabular}{c|c|c|c}
\hline \multirow{2}{*}{$\begin{array}{l}\text { Standards of } \\
\text { selecting jeans }\end{array}$} & $\mathrm{M}(\mathrm{N}=138)$ & $\mathrm{F}(\mathrm{N}=115)$ & \multirow{2}{*}{$\mathrm{t}$} \\
\cline { 2 - 4 } & Mean(standard deviation) & Mean(standard deviation) & \\
\hline Brand-valued & $-.15(1.06)$ & $.19(.89)$ & $-2.732^{\star *}$ \\
\hline Functionality-valued & $-.05(1.06)$ & $.05(.92)$ & -.788 \\
\hline Design-valued & $.15(1.03)$ & $-.18(.94)$ & $2.589^{\star \star}$ \\
\hline \hline
\end{tabular}

${ }^{\star \star} p<.01$

$<$ Table 6> Actual state of wearing jeans by gender(unit: persons(\%))

\begin{tabular}{|c|c|c|c|c|c|}
\hline \multicolumn{2}{|c|}{ Actual state Gender } & $M(N=138)$ & $F(N=115)$ & Total $(\mathrm{N}=253)$ & $x^{2}$ \\
\hline \multirow{4}{*}{$\begin{array}{l}\text { Frequency } \\
\text { of wearing }\end{array}$} & Never & $3(2.2)$ & 11(9.6) & $14(5.5)$ & \multirow{4}{*}{$20.966^{\star \star \star}$} \\
\hline & 1-2 days a week & $17(12.3)$ & $34(29.6)$ & $51(20.2)$ & \\
\hline & 3-4 days a week & $60(43.5)$ & 39(33.9) & $99(39.1)$ & \\
\hline & More than 5 days & $58(42.0)$ & $31(27.0)$ & $89(35.2)$ & \\
\hline \multirow{4}{*}{ Rise length } & High rise & $12(8.7)$ & $7(6.1)$ & 19(7.5) & \multirow{4}{*}{6.103} \\
\hline & Middle rise & $101(73.2)$ & $76(66.1)$ & $177(70.0)$ & \\
\hline & Low rise & $25(18.1)$ & $29(25.2)$ & $54(21.3)$ & \\
\hline & Very low rise & $0(0)$ & $3(2.6)$ & $3(1.2)$ & \\
\hline \multirow{4}{*}{$\begin{array}{c}\text { Number of } \\
\text { jeans } \\
\text { purchased }\end{array}$} & 1-2 jeans a year & $47(34.1)$ & $42(36.5)$ & 89(35.2) & \multirow{4}{*}{.306} \\
\hline & $3-4$ jeans & $68(49.3)$ & $53(46.1)$ & $121(47.8)$ & \\
\hline & $5-6$ jeans & 19(13.8) & $17(14.8)$ & $36(14.2)$ & \\
\hline & More than 7 jeans & $4(2.9)$ & $3(2.6)$ & $7(2.8)$ & \\
\hline
\end{tabular}

${ }^{* \star *} p<.001$ 
female students and in the frequency of wearing jeans 3-4 days a week was highest followed by more than 5 days, while female students showed 3-4 days a week highest followed by 1-2 days a week. Accordingly $85.5 \%$ of male students wear jeans more than 3 days a week, which means jeans are the basic item to wear on campus. This is different from Chun Jonhsuk and Suh Minjung's study ${ }^{37)}$ which found in frequency of wearing jeans that wearing more than 3 days a week was $45.5 \%$ for women and $25.9 \%$ for men. Middle rise jeans are preferred usually, but female students prefer lower rise seemingly due to the difference of body structure. The rise length in modern trend is getting longer from very low rise. There's no significant difference in the number of jeans purchased with the highest score in 3-4 jeans for $49.3 \%$ of male students and $46.1 \%$ of female students, which is different from the result of Park Nari and Park Jaeok's study ${ }^{38)}$ which suggested 1-2 jeans a year were purchased in $51.9 \%$ and $3-4$ in $30 \%$. This refers to the fact that male students are also consumers and buyers. That is, male students also show buying behaviors that select, purchase and wear jeans fitting them.

\section{The effect of standards of selecting jeans and appearance management behavior on leisure lifestyle}

A regression analysis was used to understand the effect of leisure lifestyle on standards of selecting jeans and appearance management and the result of significant variables and explanation is shown in <Table 7$\rangle$ below. Significant variables that have significant effect on sports-activity type were brand-valued, diet management, exercise management, weight management and appearance satisfaction with the explanation of $59 \%$. Appearance satisfaction was higher with higher points of selecting popular brands which can match people around and of worrying about weight-loss by exercising regularly and having good foods for health. And the university students who select jeans of brands that match people around showed a preference on leisure activities in which they can directly participate. The variables with effect on sociality type were design-valued and weight management with explanation of $13 \%$. The students who select jeans considering balance with other clothes and jeans of design that makes their body look better, and who think it's necessary to lose weight seemed to prefer having frequent meetings with friends. Those who are sociable and who want to be slimmer than present preferred jeans of design that makes body shape look better. Brand-valued was the only variable that have effect on self-management type with explanation of $8 \%$. The students who select jeans with brand logos on them tended to manage themselves thoroughly. The variables which have significant effect on active sociality-oriented were brand-valued, design-valued, diet management and appearance satisfaction with explanation of $18 \%$. Students who have values of becoming a leader of a group and who like to get along with others seemed to select jeans of design that matches their own image and jeans of fabric in fashion, and they had good foods for health and showed high self-confidence in their appearance. And the variables affecting family-oriented were brand-valued and diet management with explanation of $9 \%$. Students who put importance on family seemed to have a good diet for a healthy life and select jeans of brands that can go well with people around. 
Park Eunhee - Cho Hyunju / Effect of Standards of Selecting Jeans and Appearance Management Behavior on

$<$ Table $7>$ The effect of standards of selecting jeans and appearance management behavior on leisure lifestyle

\begin{tabular}{|c|c|c|c|c|c|}
\hline Dependent variable & Independent variable & $\beta$ & $t$ & $\bar{F}$ & $\mathrm{R}^{2}$ \\
\hline Sports-activity type & \begin{tabular}{|c|} 
Brand-valued \\
Functionality-valued \\
Design-valued \\
Diet management \\
Exercise management \\
Weight management \\
Appearance satisfaction
\end{tabular} & $\begin{array}{l}.09 \\
-.05 \\
.02 \\
.09 \\
.72 \\
-.17 \\
.09\end{array}$ & $\begin{array}{c}2.08^{\star} \\
-1.09 \\
.51 \\
2.14^{\star} \\
17.20^{\star \star \star} \\
-4.23^{\star \star \star} \\
2.15^{\star}\end{array}$ & $20.82^{\star \star \star}$ & .59 \\
\hline Sociality type & \begin{tabular}{|c|} 
Brand-valued \\
Functionality-valued \\
Design-valued \\
Diet management \\
Exercise management \\
Weight management \\
Appearance satisfaction
\end{tabular} & $\begin{array}{l}.00 \\
.08 \\
.25 \\
-.19 \\
.06 \\
.16 \\
.02 \\
\end{array}$ & $\begin{array}{c}.07 \\
1.32 \\
4.07^{\star \star \star} \\
-3.15 \\
1.00 \\
2.62^{\star \star} \\
.32 \\
\end{array}$ & $5.06^{\star \star \star}$ & .13 \\
\hline $\begin{array}{c}\text { Self-management } \\
\text { type }\end{array}$ & \begin{tabular}{|c|} 
Brand-valued \\
Functionality-valued \\
Design-valued \\
Diet management \\
Exercise management \\
Weight management \\
Appearance satisfaction
\end{tabular} & $\begin{array}{l}.15 \\
.02 \\
.11 \\
.10 \\
-.10 \\
.09 \\
.09\end{array}$ & $\begin{array}{c}2.32^{\star} \\
.27 \\
1.76 \\
1.52 \\
-1.66 \\
1.47 \\
1.37\end{array}$ & $2.91^{\star \star}$ & .08 \\
\hline $\begin{array}{c}\text { Active } \\
\text { sociality-oriented }\end{array}$ & \begin{tabular}{|c|} 
Brand-valued \\
Functionality-valued \\
Design-valued \\
Diet management \\
Exercise management \\
Weight management \\
Appearance satisfaction
\end{tabular} & $\begin{array}{l}.06 \\
.06 \\
.06 \\
.06 \\
.06 \\
.00 \\
.06\end{array}$ & $\begin{array}{c}2.39^{\star} \\
-.25 \\
3.81^{\star \star \star} \\
2.86^{\star \star} \\
1.37 \\
1.71 \\
2.78^{\star \star}\end{array}$ & $7.45^{\star \star \star}$ & .18 \\
\hline Family-oriented & \begin{tabular}{|c|} 
Brand-valued \\
Functionality-valued \\
Design-valued \\
Diet management \\
Exercise management \\
Weight management \\
Appearance satisfaction
\end{tabular} & $\begin{array}{l}.18 \\
.07 \\
-.02 \\
.18 \\
.02 \\
.04 \\
.06 \\
\end{array}$ & $\begin{array}{l}2.96^{\star \star} \\
1.16 \\
-.35 \\
2.81^{\star \star} \\
.31 \\
.57 \\
.87 \\
\end{array}$ & $3.27^{\star \star}$ & .09 \\
\hline Material-oriented & \begin{tabular}{|c|} 
Brand-valued \\
Functionality-valued \\
Design-valued \\
Diet management \\
Exercise management \\
Weight management \\
Appearance satisfaction
\end{tabular} & $\begin{array}{l}.14 \\
-.02 \\
.13 \\
-.04 \\
.01 \\
.12 \\
-.01\end{array}$ & $\begin{array}{l}2.13^{\star} \\
-.30 \\
2.06^{\star} \\
-.65 \\
.12 \\
1.87 \\
-.12\end{array}$ & 1.89 & .05 \\
\hline
\end{tabular}

${ }^{*} p<.05,{ }^{* *} p<.01,{ }^{* * *} p<.001$ 


\section{Conclusion}

This study examined the effect of standards of selecting jeans and appearance management on leisure lifestyle subjected to university students in their 20s. To suggest marketing strategies needed for fashion market segmentation by focusing on the relationship in specific situation of standards of selecting jeans and leisure activities of university students.

First, the factor structure of each concept appeared to be brand-valued, functionality valued and design-valued for standards of selecting jeans, diet management, exercise management, weight management and appearance satisfaction. Leisure lifestyle consisted of sports activity-type, sociality-type and self-management-type while value lifestyle consisted of active sociality-oriented, family-oriented and economic feasibility-oriented.

Second, university students put importance on matching other clothes and design that makes body shape look better in selecting jeans. University students were also interested in weight and most of them were thinking of weight loss as present ideal types are all in slim body line, which requires a necessity of making them realize how to manage their appearance for living healthy through mass media. These students wanted to have meetings with friends and some leisure life to thoroughly manage themselves through language studies or overseas trips. At the same time they thought economic feasibility to be very important and put value on material affluence.

Third, female students highly preferred design which makes their body shape look better while male students think popular brands to be more important which can match people around when selecting jeans. When wearing jeans, male students prefer showing brands out on jeans to make them a symbol of the brand while female students thought matching with their body type and other clothes to be more important. A shop master can suggest customers some visualized merchandising of product and know-hows of coordination of jeans by letting customers try on products.

Fourth, the frequency of wearing jeans was found to be higher in male students than female students as a campus-wear. This is due to the change in way of thinking by gender about appearance, and male students have also become able to wear jeans which make their body shape look better with more positive effects of functions and colors than other kinds of clothes.

Fifth, students who considered popular-branded products when selecting jeans and who wanted to get themselves into shape by having good foods for health rather than by losing weight appeared to enjoy playing sports activities by themselves rather than watching those activities. That is, those who eat good food for health and choose brands of jeans that fit friends around preferred active physical activities of participating directly in sports. Those who wishes much to weigh less and who select jeans that make their body shape look better enjoyed a leisure activity of participating in social meetings. And those students who were sociable and who wanted to get slimmer preferred jeans design that make their body shape look better while those who selected jeans with brand logos on were strict in self-discipline. The university students who wanted to be a leader in a group loving to getting around with others showed high tendency of selecting jeans of the design that 
Park Eunhee - Cho Hyunju / Effect of Standards of Selecting Jeans and Appearance Management Behavior on

goes with their image and of the fabric in fashion, and they took good foods for health and had high self-confidence in their appearance. Family-oriented students had good diet habits and selected jeans of brands that match other people around. That is, those who put importance more on brand logos showed leisure activities of overseas trips or overseas language training. Those who have high self-confidence with improvement of their images by choosing designs and materials in fashion got well along with friends, had values of good leadership and chose active society-oriented leisure activities. Those who have good diet habits and chose brands of jeans which can go well with friends around chose family-oriented leisure life of enjoying with familiy members.

Based on the results above, this study is going to suggest several marketing utilization of university students as follows.

For university students who have sociality-oriented leisure activities, jeans of the design that make body shape slimmer with planned patterns for that can be suggested. For those who are strict in their discipline, marketers can suggest jeans with the logo outside to help them increase symbolically their wealth and social positions. Jeans of fabric in fashion and of the design that go with their images would match those who want to be a leader in a group. And for family-oriented students, marketers should try to offer a store place where they can enjoy shopping with family members, and products should be popular brands in wide-range of ages. This study could find that the standards of jeans-selection and appearance management behavior were related to leisure life and accordingly marketers can pursue strategic plans of appearance-related fashion industry regarding leisure.

This study has a limit for its subjects examining university students only in Daegu and Kyoungbuk area, of which results should be used carefully in extended comprehension to all consumer classes. Further studies should examine standards of selecting jeans and leisure lifestyles extending the age groups.

\section{Reference}

1) Je Eunsuk(2011), "A study on the fashion involvement, clothing selection criteria and fashion information sources of leisure activities consumers", Journal of the Korean Society of Costume, 61(7), pp.51-66.

2) Rhee Eunyoung(1997), Fashion Marketing, Kyomunsa, pp.349-358.

3) Chung Hyeiyoung(2000), "A study on college women's attitude toward and buying intention of well-known brand apparel", The Research Journal of the Costume Culture, 8(1), pp.1-14.

4) Uh Mikyung, Suh Mia(2007), "A study on the survey of production condition of jeans in casual brands". The Research Journal of the Costume Culture, 15(4), pp.702-712.

5) Park Wonsun, Lee Sunjae(1999), "A market oriented study on the wearing attitude and purchase behavior of jeans", Journal of the Korean Society of Costume, 43, pp.109-124.

6) Lee Joungsuk, Sung Sukwang(2004), “A difference of clothing behavior of jean's wearer according to the gender", The Korean Society of Clothing Industry, 6(3), pp.336-340.

7) Lim Jiyoung(2006), "Status quo analysis on the wearing practice of blue jeans according 
to women's age", The Korean Society of Clothing Industry, 8(4), pp.413-419.

8) Kim Sonhee, Kim Hyesoo, Jeon Misun(2008), "The study on actual condition and comparison of cognition college women's wearing blue jeans by change of crotch length of hipbone blue jeans", The Research Journal of the Costume Culture, 16(6), pp.1087-1098.

9) Park Eunhee, Cho Hyunju(2012), "Selfefficacy and body satisfaction according to college students' appearance management attitudes typology", The Research Journal of the Costume Culture, 20(4), pp.515-528.

10) Rhee Eunyoung, op.cit., p.351.

11) Park Wonsun, Lee Sunjae, op.cit., pp.109 $-124$.

12) Lee Joungsuk, Sung Sukwang, op.cit., pp. 336-340.

13) Lim Jiyoung, op.cit., pp.413-419.

14) Chun Jongsuk, Suh Minjung(2007), "A study on the consumer's dissatisfaction with jean pants quality and purchasing pattern", The Research Journal of the Costume Culture, 15(6), pp.929-938.

15) Kim Sonhee, Kim Hyesoo, Jeon Misun, op.cit., pp.1087-1098.

16) Park Nari, Park Jaeok(2009), "Purchasing behavior and evaluative criteria of jeans consumers", The Research Journal of the Costume Culture, 17(4), pp.548-560.

17) Cho Sunmyoung, Koh Aeran(2008), "A study on lifestyle and sportswear benefits sought according to consuming desire of sports", Journal of the Korean Society of Clothing and Textiles, 32(3), pp.418-430.

18) Rhee Eunyoung, op.cit., p.268.

19) Hong Sungtai, Park Euna(2005), "Comparison of female consumers' purchasing behavior by lifestyle types: In the case of cosmetics", Journal of Korean Marketing Association, 20(1), pp.55-89.

20) Choi Songshin, Hiroshi Katakami, Lee Gwangbae(2002), “A comparative study on the consumption cultures between the korean and the japanese new generations: Laying emphasis upon their lifestyle characteristics \& leisures", Korean Journal of Marketing, 4(4), pp.75-96.

21) Chaiy Seoii(1992), "Systematic analysis of korean life style”, Journal of Consumer Studies, 3(1), pp.46-63.

22) Moon Sookjae, et al.(2005), Leisure Culture \& Family, Shinjeong, p.20.

23) Je Eunsuk, op.cit., pp.51-66.

24) Hong Sungtai, Park Euna, op.cit., pp.55-89.

25) Ahn Jooah, Shin Myounghee(2004), "A study on lifestyle typology and the relationship between lifestyle and purchasing behavior of university students in korea", Korean Association for Advertising and Public Relations, 7(1), pp.177-209.

26) Cho Sunmyoung, Koh Aeran, op.cit., pp.418 -430 .

27) Je Eunsuk, op.cit., pp.51-66.

28) Lee Mihyang, Yoo Hwasook.(2011), "Relationship between Shangri-la syndrome and appearance management behavior. Journal of Korean Society for Clothing Industry, 13(2), pp.194-204.

29) Kim Eunjoo(2010), "A research on the appearance-management behavior in college woman", Ewha Womans University master's dissertation. p.63.

30) Lee Jinkyoung, Han Solbi, Kwon Minjung, Kim Jaehwan, \& Lee, Jiyeon.(2010), "The buying behavior of knitwear according to appearance management attitude of the male college students. The Research Journal of the Costume Culture, 18(2), pp.322-336. 
Park Eunhee - Cho Hyunju / Effect of Standards of Selecting Jeans and Appearance Management Behavior on Leisure Lifestyle

31) Hong Sungtai, Park Euna, op.cit., pp.55-89.

32) Park Eunjoo, Pyo Heesoo(2006), "Effects of shopping value on store choice behavior for golf wear", The Korean Society of Clothing Industry, 8(5), pp.545-551.

33) Kim Sonhee, Kim Hyesoo, Jeon Misun, op.cit., pp.1087-1098.

34) Hwang, Yunjung, Yoo Taisoon(2010), "The effects of sociocultural attitudes toward appearance, self-esteem, and physical attractiveness perceptiveness on weight and clothing management behaviors. Journal of the Korean Society of Clothing and Textiles. 34(11), pp.1923-1932.
35) Cho Sunmyoung, Koh Aeran, op.cit., pp.418-430.

36) Park Nari, Park Jaeok, op.cit., pp.548-560.

37) Chun Jongsuk, Suh Minjung, op.cit., pp.929938.

38) Park Nari, Park Jaeok, op.cit., pp.548-560.

접수일(2012년 12월 27일),

수정일(1차 : 2012년 12월 12일),

게재확정일(2012년 12월 19일) 